\title{
Temporal and spatial variation in the early recruitment of fucoid algae: the role of microhabitats and temporal scales
}

\author{
Morgane Lamote ${ }^{1,2}$, Ladd E. Johnson ${ }^{1, *}$ \\ ${ }^{1}$ Département de biologie and Québec-Océan, Université Laval, Québec, Québec G1K 7P4, Canada \\ ${ }^{2}$ Phycologie et Production Primaire, Université de Lille I, UMR CNRS 8013, Bât SN2, 59655 Villeneuve d'Ascq Cédex, France
}

\begin{abstract}
The recruitment of a multi-species assemblage of fucoid algae, Ascophyllum nodosum (L.) Le Jolis, Fucus vesiculosus L., and F. distichus L. ssp. edentatus (Pyl.) Powell, onto artificial substrata over different temporal and spatial scales was examined on a semi-exposed rocky shore in Québec, Canada. Measurements were taken at daily (1 d), fortnightly (15 d), and monthly (30 d) periods in 3 microhabitats (exposed rock surfaces, under adult fucoids, and in tide pools) from July through September in 3 consecutive years (1998 to 2000). Recruitment was spatially and temporally variable among months and years with much less recruitment in 1998. Recruitment was consistently lowest in September. The density of reproductive adults did not generally affect the rate of recruitment, but the rate of recruitment was negatively correlated with wind speed, a possible indicator of wave action. Among microhabitats, the recruitment was over 10 to 50 times greater under the canopy relative to exposed surfaces and tide pools. Mortality of outplanted embryos was only slightly higher outside the canopy, which suggests that it is limited dispersal and not differential survival that leads to high numbers of recruits under the canopy. There were, however, no differences in the numbers of recruits accumulating from 1 to $30 \mathrm{~d}$, suggesting that overall post-settlement mortality rates are extremely high.
\end{abstract}

KEY WORDS: Algae $\cdot$ Intertidal zone $\cdot$ Population dynamics $\cdot$ Rocky shores $\cdot$ Seaweed $\cdot$ Wind Resale or republication not permitted without written consent of the publisher

\section{INTRODUCTION}

The dynamics of a population can depend critically on the rate at which new individuals are added, i.e. the process of recruitment. In benthic marine algae, recruitment includes the dispersal and settlement of propagules (i.e. spores or zygotes), and their subsequent survival, and thus the dynamics of recruitment will depend, in part, on the temporal and spatial variation in the availability of propagules (Roughgarden et al. 1988). Unfortunately, the small size of most algal propagules makes it difficult to assess this variation, and often, the entire process has been inferred from the distribution of juvenile stages (Reed et al. 1988, Archambault \& Bourget 1999), which can lead to incorrect interpretation of the true patterns of settlement (Keough \& Downes 1982). It is also now apparent that the timescale over which observations are made can affect the interpretation of different ecological processes. While this concern has been raised in studies of invertebrates and fish (e.g. Caffey 1984, Choat et al. 1988, Wilson \& Osenberg 2002), very few studies of marine algae have closely examined the early events surrounding settlement and early survival (e.g. Edelstein \& McLachlan 1975, Reed \& Foster 1984, Pearson \& Brawley 1996, Johnson \& Brawley 1998; reviewed by Vadas et al. 1992). During the period from the initial settlement of propagules to the first appearance in the population, algae are likely to experience substantial mortality (Brawley \& Johnson 1991, Worm et al. 2001), which can vary greatly in time and space (Ang 1991). Given that survival and development of the early postsettlement stages are required for the eventual establishment of adults, it is critical to understand this pro- 
cess if we are to understand the dynamics of adult populations (Vadas et al. 1992).

Recruitment must often operate in 2 very different modes, the first being the continual replacement of individuals lost from the population and the second being the massive re-establishment of disturbed areas (Dudgeon \& Petraitis 2001). The dynamics of these 2 situations are likely to vary considerably for 2 reasons: (1) the availability of propagules may differ as dispersal in some species of algae has been shown to be very limited (Santelices 1990, Norton 1992), and (2) the microenvironments into which propagules settle are vastly different - moist but with limited light under the adult canopy and dry and bright on recently disturbed surfaces. Survival among such microhabitats can vary from 0 to $100 \%$ over spatial scales as small as $10 \mathrm{~cm}$ (Brawley \& Johnson 1991) with those under adult canopies being the most benign, at least in the short term.

The rocky intertidal communities of the Gaspé Peninsula, Québec, are severely affected by ice scour (Archambault \& Bourget 1983), and sessile invertebrates and perennial algae, principally fucoids, are generally restricted to low-lying areas between topographical high points. Interannual variation in this disturbance regime can, however, create patches within established beds of fucoids. This situation thus provides an excellent opportunity to study these 2 modes of recruitment in a perennial intertidal algal community. In the present study we examined the temporal and spatial dynamics of early recruitment in a complex of fucoid algae over a $3 \mathrm{yr}$ period. By examining this process over different periods and within different microhabitats, we aimed to determine the spatial and temporal scales at which variation was greatest and infer the processes (e.g. limited dispersal, high mortality) underlying this variation.

\section{MATERIALS AND METHODS}

The study was conducted in the intertidal zone at Pointe-Mitis $\left(48^{\circ} 41^{\prime} \mathrm{N}, 68^{\circ} 2^{\prime} \mathrm{W}\right.$; near Mont Joli, Québec, Canada), a semi-sheltered shore consisting of a series of rocky ridges interspersed with consolidated boulder fields or tide pools (Bourget et al. 1985). These boulder fields and the lower portions of adjacent ridges were dominated by 3 species of fucoid algae, Ascophyllum nodosum (L.) Le Jolis, Fucus vesiculosus L., and F. distichus L. ssp. edentatus (Pyl.) Powell, that formed dense canopies covering up to $80 \%$ of the substratum. These perennial algae are not able to colonize the more exposed rocky surfaces (e.g. the top portions of ridges) due to ice scour and thus only occur in areas protected from abrasion by ice (Archambault \& Bour- get 1983). Tides are semi-diurnal at this site with a tidal range of $4.0 \mathrm{~m}$.

Five study areas were haphazardly selected along a $150 \mathrm{~m}$ stretch of the mid-intertidal zone (see Lamote 2003 for specific locations). Areas were separated by $\geq 20 \mathrm{~m}$ and were naturally isolated by the rocky ridges that dominate this shoreline. Fucoid cover at the time of selection ranged from 25 to $80 \%$ cover. Although individuals of all 3 species were usually present, most areas were dominated by a single species at any given time.

Recruitment was estimated over 3 yr (1998 to 2000) by the use of artificial substrata. These substrata were identical to those used in earlier studies (Johnson 1994, Johnson \& Brawley 1998) and consisted of small, white disks (4 mm thick, $20 \mathrm{~mm}$ diameter) fabricated from Sea Goin' Poxy Putty (Permalite Industries), a filled epoxy putty, by a molding and casting process in which the top surface was given the rough texture of sandpaper (Johnson 1994). Holes were drilled and tapped so that the disks could be attached with small stainless steel machine screws to small, polycarbonate base plates (3 $\mathrm{mm}$ thick, $85 \mathrm{~mm}$ diameter) that could each hold 6 disks. These plates were attached to the substratum using stainless steel screws driven into plastic wall anchors placed in holes drilled into the rock surface at each location (Johnson 1994).

Disks were set out for 3 distinct time scales: 1, 15, and $30 \mathrm{~d}$ periods. For each period, 2 disks were set out on a single plate installed at each location, and at any given location, all the disks for the 1,15, and $30 \mathrm{~d}$ periods resided on the same base plate (i.e. 6 disks per base plate; 2 for each period). Manipulation of disks always began as areas were being uncovered by the ebbing tide, but due to the number of locations (see next paragraph) and the distance between areas, the collection and replacement of disks took 2.5 to $3.5 \mathrm{~h}$ and thus could not be done at a quasi-simultaneous moment as in earlier studies (Pearson \& Brawley 1996, Johnson \& Brawley 1998). Areas were, however, always visited in the same order although individual locations within a given area were treated as they were located. After collection, disks were transported to the laboratory where all attached fucoid zygotes were counted within hours using a stereomicroscope. For $1 \mathrm{~d}$ recruitment, this protocol was repeated for 5 consecutive days during each spring tide series (i.e. twice each lunar month) for the 3 mo period in which fucoid algae are reproductive at this site (July to September). Observations could not be made for additional days because the period of low tide was only long enough during spring tides for the time required to visit all areas. For measurements of 15 and $30 \mathrm{~d}$ recruitment, a similar procedure was followed but with the 2 disks recovered and replaced after 15 and $30 \mathrm{~d}$ periods, respectively. After being sampled, disks were 
reused, but first scrubbed with a toothbrush in fresh water to remove any embryos.

Within each area recruitment of fucoids was examined in 3 distinct microhabitats: emergent rock surfaces covered by a canopy of adult fucoids, emergent rock surfaces not covered by a canopy (representing scoured areas), and submergent rock surfaces without a canopy; henceforth 'canopy', 'exposed', and 'tide pool' microhabitats, respectively. This latter microhabitat was selected to control for effects of desiccation that were expected to be higher outside the adult canopy (Brawley \& Johnson 1993) but was not included in the design until 1999. Eight locations were haphazardly selected in the canopy microhabitat, 2 in the exposed and 2 in the tide pool microhabitats under the condition that they were separated from each other by $\geq 1 \mathrm{~m}$. This experimental design was unbalanced but permitted a better estimate of temporal variation in recruitment that was expected to occur primarily under the canopy (Johnson \& Brawley 1998).

To estimate mortality rates, we also outplanted embryos of Fucus vesiculosus on putty disks in all 3 years. Experiments were limited to this species as its reproductive period spanned all $3 \mathrm{mo}$, and we assumed that mortality in this species would generally reflect that of the other species, given the overall similarity of their response to emersion stressors (Lamote et al. 2007). To obtain embryos, receptacles (the reproductive structures of fucoid algae) were collected from the field and stored in the dark at $10^{\circ} \mathrm{C}$. Care was taken to avoid algae with obvious epiphytes (e.g. diatoms), but before any use, the receptacles were scrubbed with a toothbrush and rinsed with seawater to remove epiphytes from the receptacle surface. To induce gamete release, receptacles were then osmotically shocked by airdrying for 20 min followed by rinsing in cold fresh water for $5 \mathrm{~min}$. They were then placed into filtered $(5 \mu \mathrm{m})$ seawater where gamete release and fertilization occurred. After the release of gametes, but before attachment began (which typically occurs 4 to $5 \mathrm{~h}$ after fertilization [Kropf et al. 1989]), the 'solution' of seawater and zygotes was gently poured over putty disks and then left overnight in the dark at $4{ }^{\circ} \mathrm{C}$ to allow attachment. The following morning attached embryos (now 16 to 20 h old) were counted and then outplanted into the field at the beginning of the low tide period by attaching disks to base plates located in the 3 microhabitats described in the previous paragraph ('canopy', 'exposed', and 'tide pool'). Six disks were attached to each of 2 replicate base plates separated by $1 \mathrm{~m}$ in each microhabitat in all 5 study areas (i.e. 6 disks $\times 2$ plates $\times$ 3 microhabitats $\times 5$ areas $=180$ disks for each experiment). Disks were recovered the following day at the same tidal time, and the number of embryos counted again. Data from the 12 disks in each microhabitat were averaged to give 10 replicates of each MicrohabitatMonth combination ( 5 areas $\times 2$ experiments $\mathrm{mo}^{-1}$ ).

The abundance of reproductive fucoid algae was determined twice monthly during the periods when recruitment measurements were taken. The density of mature adults was estimated using three $625 \mathrm{~cm}^{2}$ quadrats haphazardly located within each study area. The number of receptacles was also determined for each mature adult fucoid found within the quadrat. Hourly wind speed and air temperatures were obtained from the Mont Joli airport, located $15 \mathrm{~km}$ from the field site, and were considered an approximation of the weather conditions at the field site.

Because of the unbalanced design and violation of certain ANOVA assumptions due to the very low recruitment outside of adult stands, we limited our analysis of temporal and spatial variation to the recruitment that occurred in the canopy microhabitat. We used a mixed ANOVA model (SAS v. 8.2) to analyze logtransformed data $(x+1)$ on the rate of recruitment at different periods (fixed; 1, 15, and $30 \mathrm{~d}$ ), months (fixed; July, August, and September) and years (fixed; 1998, 1999, and 2000) in different areas (random; 1 to 5). To further avoid an unbalanced design, data used for this analysis were the mean monthly values for each period (i.e. values used for each plate were the mean of the 2 disks used for each period averaged over 2 and $10 \mathrm{~d}$ for 15 and $1 \mathrm{~d}$ periods, respectively). Prior to analysis, homoscedacity and normality assumptions were verified by the Shapiro-Wilks test. An LSD (Least Significant Difference) multiple comparisons test (using the square means of the Type III) was used for separation of means. Separate mixed analyses of covariance (ANCOVAs) using temperature, wind speed, density of mature plants, and density of receptacles as covariates were conducted to assess the effect of these factors on recruitment because of unbalanced designs due to missing data (e.g. missing wind speed data). To assess the variation of the mortality in the 3 microhabitats, a 3-way ANOVA (Year, Month, Microhabitat) was performed. Homogeneity and normality assumptions were again determined by the Shapiro-Wilks test. Contrasts were performed using Scheffé tests with adjustments to the critical F-value appropriate for unplanned contrasts. Linear regressions were performed using Statistica version 6 (Stathoff).

\section{RESULTS}

The $1 \mathrm{~d}$ recruitment of fucoid propagules varied significantly with respect to years, months, and areas (Tables 1 \& 2, Fig. 1). Recruitment was much greater in 1999 and 2000 relative to 1998, and among the 3 mo was consistently lowest in September. In 1998, recruit- 
Table 1. ANOVA (Proc Mixed) showing the effects of Area, Month, Year, and Period on the recruitment of fucoid algae under the adult canopy. Data used for the analysis consisted of the mean values for each of 8 plates located under the fucoid canopy for a given Area-Month-Year combination, (i.e. the average of the 2 disks plate ${ }^{-1}$ over the 10,2 , and 1 samplings for 1, 15, and $30 \mathrm{~d}$ recruitment periods, respectively)

\begin{tabular}{|lrrr|}
\hline Source of variation & df & $F$ & \multicolumn{1}{c|}{$\mathrm{p}$} \\
\hline Area & 4 & 44.3 & $<0.01$ \\
Year & 2 & 6.8 & 0.01 \\
Year $\times$ Area & 8 & 16.4 & $<0.01$ \\
Month & 2 & 54.6 & $<0.01$ \\
Month $\times$ Area & 8 & 0.5 & 0.82 \\
Year $\times$ Month & 4 & 5.4 & 0.01 \\
Year $\times$ Month $\times$ Area & 16 & 0.7 & 0.80 \\
Period & 2 & 0.1 & 0.55 \\
Area $\times$ Period & 8 & 2.6 & 0.02 \\
Year $\times$ Period & 4 & 1.1 & 0.38 \\
Year $\times$ Area $\times$ Period & 16 & 1.9 & 0.06 \\
Month $\times$ Period & 4 & 1.2 & 0.34 \\
Month $\times$ Area $\times$ Period & 16 & 1.3 & 0.25 \\
Year $\times$ Month $\times$ Period & 8 & 1.1 & 0.41 \\
Error & 977 & & \\
Corrected total & 1079 & & \\
\hline
\end{tabular}

Table 2. Conditional effect of Month for each year and conditional effect of Year for each month showing variation of recruitment given the significant interaction between these 2 factors

\begin{tabular}{|lcrrrr|}
\hline Source of variation & Month & Year & df & $F$ & $\mathrm{p}$ \\
\hline Year $\times$ Month & & 1998 & 2 & 10.28 & $<0.01$ \\
Year $\times$ Month & & 1999 & 2 & 14.37 & $<0.01$ \\
Year $\times$ Month & 2000 & 2 & 13.99 & $<0.01$ \\
Year $\times$ Month & July & & 2 & 6.22 & 0.01 \\
Year $\times$ Month & August & & 2 & 2.16 & 0.12 \\
Year $\times$ Month & September & & 2 & 0.59 & 0.55 \\
\hline
\end{tabular}

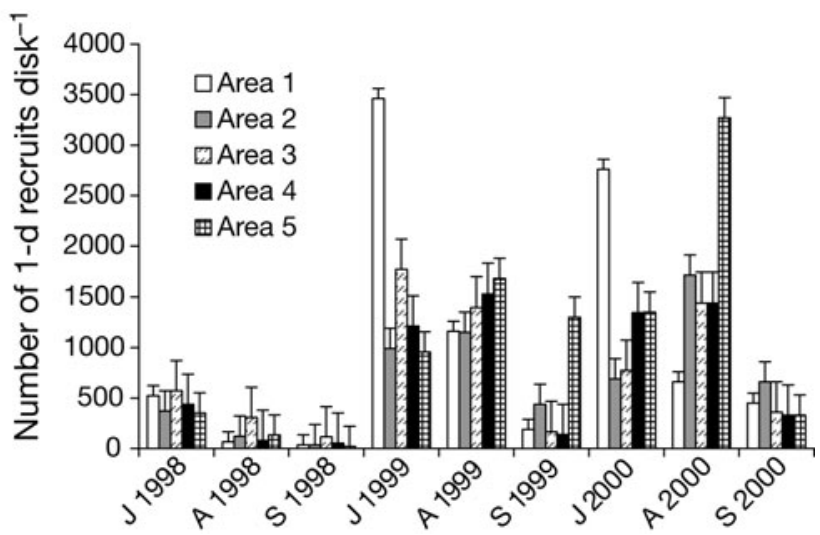

Fig. 1. Daily (1 d) recruitment of fucoid embryos onto epoxy disks under an adult canopy in 5 study areas in July (J), August (A), and September (S) over a 3 yr period. Bars represent the mean $\pm \mathrm{SE}$ of the 8 plates located in each area. The values used for each plate were the average of the ten $1 \mathrm{~d}$ periods sampled within a given month ment was highest in July, but in the subsequent years of higher recruitment, July and August levels were similar overall (Table 2). Within a given month, $1 \mathrm{~d}$ recruitment was generally similar among the different areas, except for extremely high values (2500 to 3500 zygotes per disk) for single areas during some months (i.e. Area 1 in July of both 1999 and 2000 and Area 5 in August 2000). Patterns of 15 and 30 d recruitment of fucoid propagules generally paralleled those of $1 \mathrm{~d}$ recruitment, but 15 and 30 d recruitment was higher in 1998 (especially in July) and lower in 2000 (especially in August and September) relative to $1 \mathrm{~d}$ recruitment patterns (Figs. $2 \& 3$ ).

The number of recruits that accumulated over the entire month period was generally equal to or less than the daily average (Fig. 4) except in August and September 2000 when $1 \mathrm{~d}$ recruitment far exceeded $30 \mathrm{~d}$ recruitment. There was a similar lack of accumulation over the $15 \mathrm{~d}$ period as well (data not shown). As

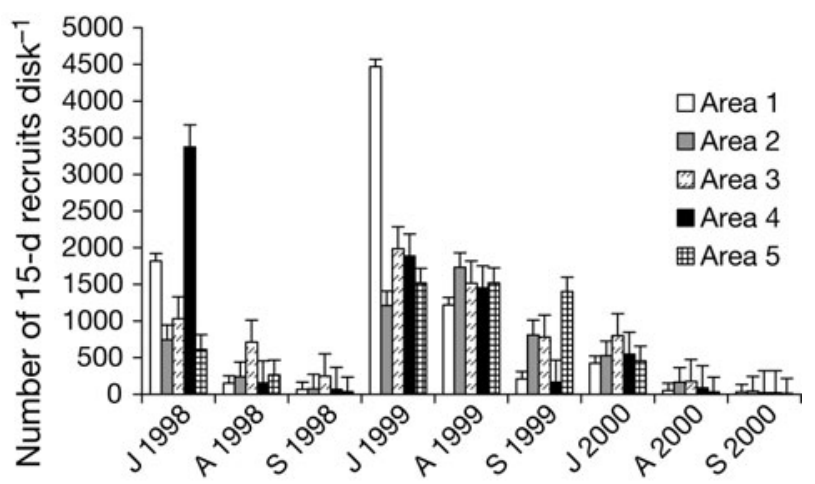

Fig. 2. Fortnightly (15 d) recruitment of fucoid embryos onto epoxy disks under an adult canopy in 5 study areas in July $(\mathrm{J})$, August (A), and September (S) over a 3 yr period. Bars represent the mean \pm SE of the 8 plates located in each area. The values used for each plate were the average of the two $15 \mathrm{~d}$ periods sampled within each month

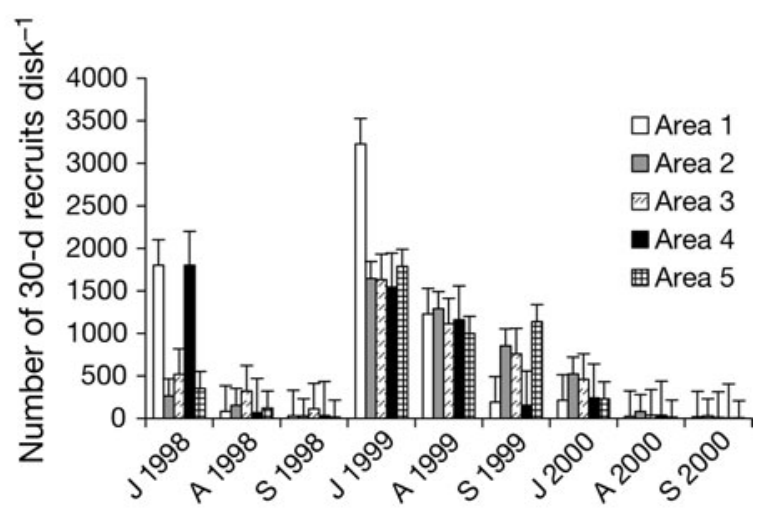

Fig. 3. Monthly (30 d) recruitment of fucoid embryos onto epoxy disks under an adult canopy in 5 study areas in July $(\mathrm{J})$, August (A), and September (S) over a 3 yr period. Bars represent the mean $\pm \mathrm{SE}$ of the 8 plates located in each area 


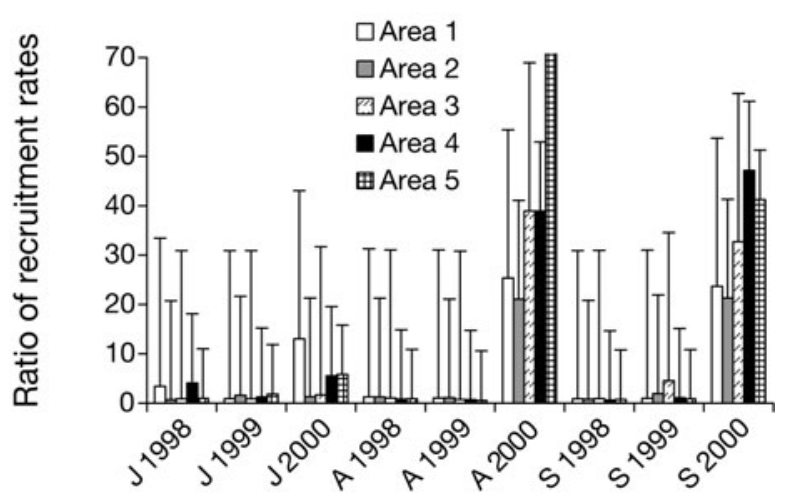

Fig. 4. Ratio of $1 \mathrm{~d}$ to $30 \mathrm{~d}$ recruitment rates of fucoid propagules on epoxy disks in 5 study areas in July (J), August (A), and September (S) over a $3 \mathrm{yr}$ period. Bars represent the mean \pm SE of the recruitment on the 8 plates located in each area, which, in the case of 1 d recruitment, was calculated as the average of the ten $1 \mathrm{~d}$ periods sampled in each month. Note that the $y$-axis has been scaled to show the smaller values, and that the value for August 2000 was 250

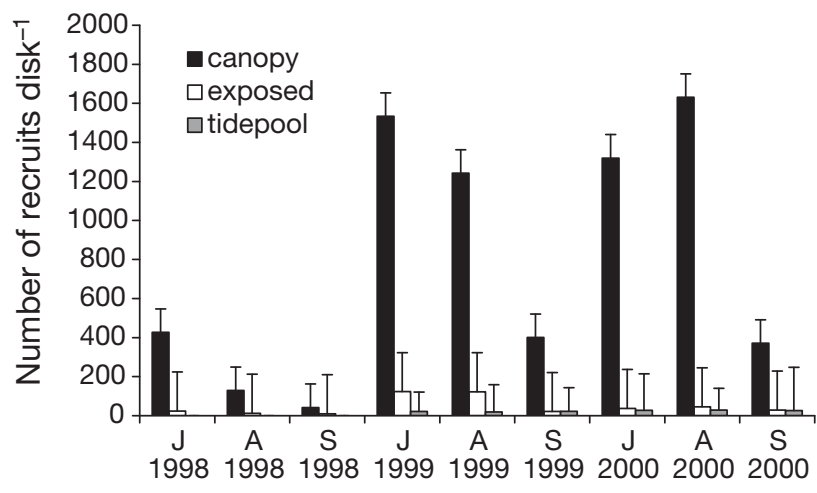

Fig. 5. Daily (1 d) recruitment of fucoids onto epoxy disks in 3 intertidal microhabitats in July (J), August (A), and September (S). Bars represent the mean $\pm \mathrm{SE}$ of the plates located in each microhabitat pooled for all 5 study areas, using the average value for the ten $1 \mathrm{~d}$ periods sampled

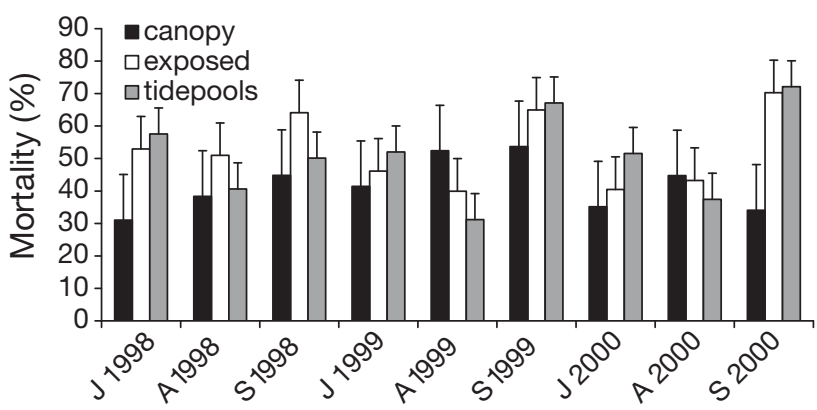

Fig. 6. Mortality of outplanted 16 to $20 \mathrm{~h}$ old fucoid zygotes in July (J), August, (A) and September (S) in 3 intertidal microhabitats. Bars represent mean \pm SE $(n=10)$ embryos were not distinguished from zygotes in these counts, we cannot assess if the algae on the 15 or $30 \mathrm{~d}$ disks had just settled (i.e. zygotes) or were established (i.e. embryos). Overall there was a significant correlation between $1 \mathrm{~d}$ recruitment and the $30 \mathrm{~d}$ recruitment $(\mathrm{r}=0.43 ; \mathrm{p}=0.029 ; \mathrm{n}=45)$. This relationship was weakest in 2000 when daily rates remained high, but $30 \mathrm{~d}$ rates were even lower than in 1998 (Fig. 4). There was also a relationship between 15 and 30 d data $(\mathrm{r}=$ $0.85 ; \mathrm{p}=0.08 ; \mathrm{n}=45$ ).

When examined by different microhabitats, the $1 \mathrm{~d}$ recruitment of fucoid zygotes was 10- to 50-fold higher under the adult canopy than in tide pools or exposed rock surfaces except during months of low recruitment, e.g. September (Fig. 5). Mortality of outplanted 16 to $20 \mathrm{~h}$ old embryos was remarkably stable and averaged 40 to $50 \%$ across all years and all months (Fig. 6). The 3-way statistical interaction was, however, significant (Table 3), but there was no clear pattern among the various contrasts except for mortality rates being lower under the canopy compared to the other 2 microhabitats ( $p<0.005$ for 10 of 18 contrasts) and higher mortality in September relative to July ( $p<$ 0.005 for 7 of 9 contrasts).

The density of mature algae varied consistently across the season (Fig. 7). Ascophyllum nodosum was most abundant in July with some mature plants found only in August. The abundance of Fucus vesiculosus was high in July and August but then declined during September. Finally, F. distichus ssp. edentatus had the reverse pattern: low abundance in July but then high abundance during August and September. Interannual variation did occur but mostly in the months of low fucoid abundance. An exception was the low abundance of F. distichus ssp. edentatus in August 2000,

Table 3. ANOVA (Proc Mixed) showing the effects of Year, Month, and Microhabitat on the mortality of fucoid zygotes outplanted for $1 \mathrm{~d}$ into 3 contrasting microhabitats: under the adult canopy, outside the adult canopy, and in tide pools. Data used for the analysis consisted of the mean values for 12 disks located on 2 plates in each microhabitat. Outplants were performed twice each month into 5 areas to provide 10 replicates of each Year-Month-Microhabitat combination

\begin{tabular}{|lrrr|}
\hline Source of variation & df & \multicolumn{1}{c|}{$F$} & \multicolumn{1}{c|}{$p$} \\
\hline Year & 2 & 1.34 & 0.2640 \\
Month & 2 & 86.86 & $<0.0001$ \\
Year $\times$ Month & 4 & 5.34 & 0.0004 \\
Microhabitat & 2 & 37.93 & $<0.0001$ \\
Year $\times$ Microhabitat & 4 & 8.38 & $<0.0001$ \\
Month $\times$ Microhabitat & 4 & 25.83 & $<0.0001$ \\
Year $\times$ Month $\times$ Microhabitat & 8 & 5.52 & $<0.0001$ \\
Error & 243 & & \\
Corrected total & 269 & & \\
\hline
\end{tabular}




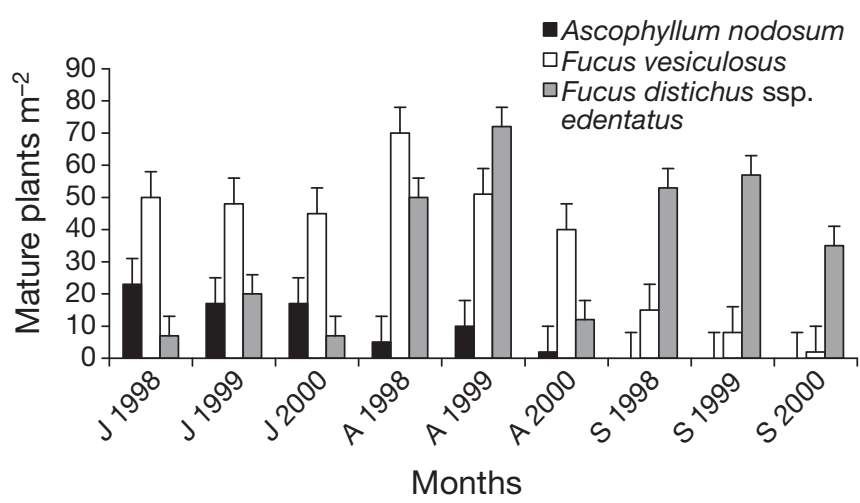

Fig. 7. Adult densities of all 3 species combined in July (J), August (A) and September (S): Ascophyllum nodosum, Fucus vesiculosus, and Fucus distichus ssp. edentatus. Bars represent mean $\pm \mathrm{SE}(\mathrm{n}=15)$

which was $25 \%$ of the average abundance of the 2 previous years. The density of receptacles (pooled for all species) peaked in August for the first 2 years (data not shown; see Lamote 2003) when the 2 Fucus spp. were most abundant. August receptacle abundance was substantially lower in 2000, essentially at the same level of the other months. A correlation was not seen between the abundance of adults of all 3 species combined and daily recruitment (data not shown), but when examined at the species level, a positive correlation was found for 1 species, $F$. distichus ssp. edentatus $\left(\mathrm{R}^{2}=0.76 ; \mathrm{p}=0.06, \mathrm{n}=9\right.$, i.e. the average data from all sites for each of 3 mo over 3 yr). No effect of adult density or receptacle density on recruitment was observed, however, in the ANCOVA (Table 4). There was significant effect of wind speed on recruitment (Table 5) with decreasing daily recruitment with increasing wind speed $\left(R^{2}=0.76, p<0.05, n=130\right.$, Fig. 8). There was no significant correlation with air temperature.

Table 4. ANCOVA (Proc Mixed) showing the effect of receptacles and density of mature adults on recruitment in canopy microhabitats. Adult and receptacle densities were used as covariates

\begin{tabular}{|lrrr|}
\hline Source of variation & df & \multicolumn{1}{c|}{$F$} & \multicolumn{1}{c|}{$\mathrm{p}$} \\
\hline Year & 2 & 39.04 & $<0.01$ \\
Month & 2 & 40.41 & $<0.01$ \\
Year $\times$ Month & 4 & 21.73 & 0.01 \\
Period & 2 & 0.63 & 0.53 \\
Year $\times$ Period & 4 & 0.44 & 0.77 \\
Month $\times$ Period & 4 & 0.21 & 0.93 \\
Year $\times$ Month $\times$ Period & 8 & 0.18 & 0.99 \\
Receptacles & 1 & 0.17 & 0.68 \\
Density of mature adults & 1 & 0.72 & 0.39 \\
Error & 106 & & \\
Total & 134 & & \\
\hline
\end{tabular}

Table 5. ANCOVA (Proc Mixed) showing the effect of the wind speed on recruitment during 3 years, 3 months, and on 3 periods of recruitment $(1,15$, or $30 \mathrm{~d}$ old embryos). Wind speed was used as a covariate

\begin{tabular}{|lrrrr|}
\hline Source of variation & df & MS & \multicolumn{1}{c}{$F$} & \multicolumn{1}{c}{$\mathrm{p}$} \\
\hline Year & 2 & 9.24 & 47.44 & $<0.001$ \\
Month & 2 & 9.63 & 49.45 & $<0.001$ \\
Year $\times$ Month & 4 & 0.34 & 1.76 & 0.142 \\
Period & 2 & 0.12 & 0.64 & 0.530 \\
Year $\times$ Period & 4 & 0.09 & 0.47 & 0.757 \\
Month $\times$ Period & 4 & 0.04 & 0.22 & 0.925 \\
Year $\times$ Month $\times$ Period & 8 & 0.04 & 0.19 & 0.992 \\
Wind & 1 & 0.92 & 4.74 & 0.032 \\
Error & 107 & 0.19 & & \\
\hline
\end{tabular}

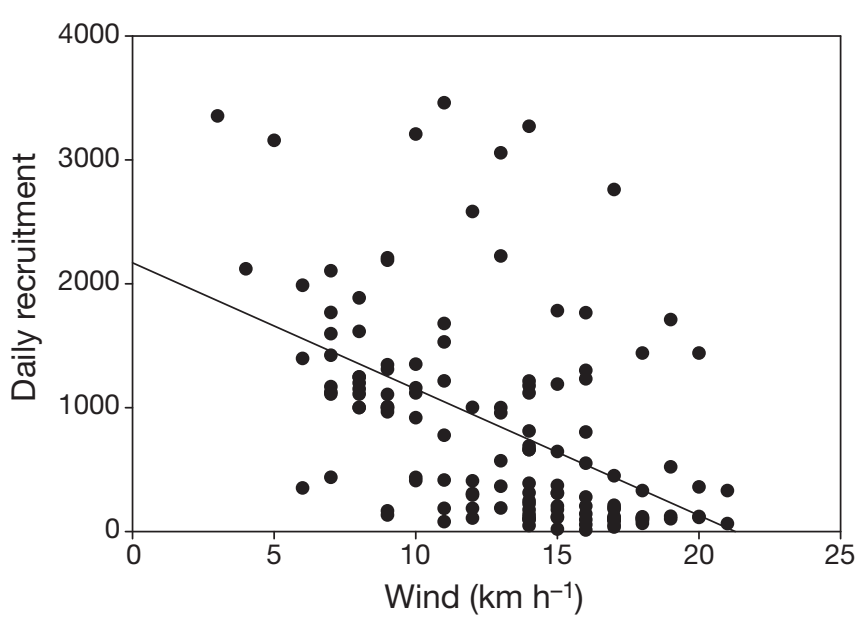

Fig. 8 Number of $1 \mathrm{~d}$ fucoid recruits vs. wind speed during summer over a 3 yr period; $r^{2}=0.76, p<0.05, n=130$

\section{DISCUSSION}

Given the limited dispersal of fucoid algae, temporal variation in recruitment should depend ultimately on the abundance and fecundity of adults and early survival of propagules. Among different years and different months, we did not, however, find a strong relationship between the temporal abundance of receptacles or adults (little variation) and rates of recruitment (much variation), perhaps because we did not assess the abundance or maturity of gametes within receptacles, which can vary between months (Ang 1991, Wright et al. 2004). Moreover, we could not distinguish embryos at the species level; thus the specific contributions of individual species could not be discriminated. Temporal variation in the release of gametes (see Brawley et al. 1999 and Pearson \& Serrão 2006 for reviews) occurs over much shorter time scales ( 1 to $14 \mathrm{~d}$ ) than we addressed here and should have been averaged out by our sampling design (i.e. $10 \mathrm{~d}$ during each month). 
Post-settlement mortality rates as measured by our outplanted zygotes also varied significantly among months and years but not nearly to the same degree that recruitment varied. Moreover, any trends were the opposite of what would be predicted, i.e. mortality rates were highest in 1999, the year with maximal recruitment. Our mortality estimates did not, however, include the critical period just after settlement. Attachment of the zygotes of these species generally occurs 4 to $6 \mathrm{~h}$ after fertilization when adhesive polymers are formed (Quatrano 1980). In the field zygotes were rarely out of water for more than 5 to $6 \mathrm{~h}$ whereas our outplanted zygotes had 16 to $20 \mathrm{~h}$ in the laboratory for attachment. Thus, variation in hydrodynamic forces immediately after settlement could explain the observed variation in recruitment. Hydrodynamic forces vary substantially at this site (Addy \& Johnson 2001) both spatially and temporally, and the negative correlation between wind forces and recruitment could be the result of reduced settlement or increased dislodgment under conditions of increased wind-driven water movement as observed elsewhere (Vadas et al. 1990). Water motion can also inhibit gamete release (e.g. Pearson \& Brawley 1996), but again such variation would have occurred at shorter time scales.

The lack of any accumulation of recruits on disks set out for 15 or $30 \mathrm{~d}$ periods shows that mortality rates were extremely high for these propagules. The numbers of zygotes on 15 or $30 \mathrm{~d}$ disks were surprising low; indeed, they were not different from or were even below average daily values, suggesting that there was no measurable recruitment occurring. (It should be kept in mind, however, that our study involved artificial substrata which may not precisely mimic the natural rock surface, especially in terms of attachment.) The inference of high mortality rates is consistent with our experiments that demonstrated that mortalities of 30 to $70 \%$ occurred over a single day for young stages (initially $18 \mathrm{~h}$ old). As discussed in the previous paragraph, mortality rates are probably even higher during the period immediately after settlement, but if this daily rate of mortality continued, only 1 recruit in 10000 would survive $10 \mathrm{~d}\left(0.5^{10}=0.0001\right)$ leading to trivial accumulation over time. Although mortality was slightly lower in the canopy microhabitat, large differences were not seen between the different microhabitats, which suggests that neither sweeping by adult fronds in the canopy microhabitat nor desiccation in the exposed microhabitat were important factors involved in the mortality of this stage. Thus another factor common to all 3 microhabitats must be responsible. Again dislodgment by water motion is the most likely candidate although certain grazers (littorinid snails and gammarid amphipods) are ubiquitous components of this community.
These results clearly demonstrate that shorter-term measurements are needed for estimating settlement rates of these algae as there was no accumulation of recruits over time relative to rates of daily recruitment. Estimates of settlement rates based on recruitment over longer periods of time would thus be quite misleading. Without direct observations of settlement, measures of $1 \mathrm{~d}$ recruitment are then our best estimates of settlement although they are conservative as there may be substantial loss during the $24 \mathrm{~h}$ period that disks were in place (see above). We observed continual settlement during the study period, typically varying from $10 \mathrm{~s}$ to 100 s of zygotes $\mathrm{cm}^{-2} \mathrm{~d}^{-1}$, but at times reaching 1000 s of zygotes $\mathrm{cm}^{-2} \mathrm{~d}^{-1}$. From these data we can calculate annual rates of settlement assuming that the 3 mo period encompassed the entire reproductive season and that the days we sampled were representative (e.g. if our $5 \mathrm{~d}$ sampling periods coincided with lunar or semi-lunar peaks in gamete release [e.g. Andersson et al. 1994, Creed et al. 1996, Pearson \& Brawley 1996, Serrão et al. 1996, Johnson \& Brawley 1998; see review by Pearson \& Serrão 2006], then we would have overestimated annual production; peaks in settlement do not, however, always fall during the time of new or full moon [e.g. Johnson \& Brawley 1998]). We thus estimate that the total settlement during the reproductive season was from $0.9 \times 10^{7}$ to $2.6 \times$ $10^{7}$ zygotes $\mathrm{m}^{-2} \mathrm{yr}^{-1}$ (= daily average $\times 30 \mathrm{~d} \times 3 \mathrm{mo}$ ) depending on the year, which is consistent with earlier studies of fucoid algae (Ang 1991, Creed et al. 1996) and reinforces the idea that post-settlement mortality rates are extremely high in these algae (Vadas et al. 1990, Wright et al. 2004).

Spatial variation in recruitment was also observed in the present study at both spatial scales examined, among the 5 different study areas and among the $3 \mathrm{mi}-$ crohabitats. Variation among areas was mostly due to high recruitment in 2 of the 5 areas during certain months, but there was no consistent pattern over time. Patterns were much clearer among microhabitats where there was always 1 to 2 orders of magnitude higher recruitment under the adult canopy. These observations are consistent with previous studies showing the limited dispersal of fucoid zygotes (Johnson \& Brawley 1998, Dudgeon et al. 2001, Arrontes 2002). The underlying mechanism is likely the release of gametes during low tide or periods of calm water conditions as observed generally in fucoid algae (e.g. Brawley 1992, Ladah et al. 2003; reviewed by Brawley et al. 1999, Pearson \& Serrão 2006), which should increase settlement of zygotes near or under adults and would explain our observations of much higher $1 \mathrm{~d}$ recruitment within the canopy. We did not systematically examine recruitment patterns on natural surfaces, but recruitment on bare rock surfaces is rare at 
this site and usually only occurred in lower zones on rock faces protected from direct sunlight (Lamote 2003). Higher recruitment of juvenile stages within adult stands of fucoid algae has also been observed elsewhere (Lubchenco 1983, McCook \& Chapman 1991, Vadas et al. 1992, De Vogelaere \& Foster 1994, Worm \& Chapman 1996), and this pattern has often been ascribed to higher mortality in other microhabitats due to herbivory (Hawkins 1981, Lubchenco 1983, Cervin et al. 2004, 2005) or physical conditions (e.g. desiccation during low tide [Brawley \& Johnson 1991, 1993], dislodgment during high tide [Vadas et al. 1992]). Our results suggest that dispersal and sources of mortality acting shortly after settlement may be fundamentally more important in determining this pattern unless areas without an algal canopy are limited in spatial extent (Cervin et al. 2005).

The high spatial and temporal variation in recruitment has been observed in previous studies of recruitment in algae (Ang 1991, Vadas et al. 1992, Wright \& Steinberg 2001, Wright et al. 2004). Such variation can be an important determinant of local population abundance, but other factors such as density-independent mortality after settlement also play a role, and the relative importance of these processes can vary in time and space (Wright \& Steinberg 2001, Steen \& Scrosati 2004). Lazo et al. (1994) found that only $0.01 \%$ of Ascophyllum nodosum survived annually and that the mortality was largely due to molluscan herbivores. Our results suggest also that the majority of mortality is occurring shortly after settlement and is likely due to wave dislodgment (Vadas et al. 1990, Serrão et al. 1996). Other causes such as desiccation (Schonbeck \& Norton 1980, Santelices 1990, Brawley \& Johnson 1991, Chapman 1995) or density-dependent competition (Ang \& De Wreede 1992, Kendrick 1994, Steen \& Scrosati 2004) are less likely possibilities, although the effect of grazing (e.g. Lubchenco 1983, Barker \& Chapman 1990, Benedetti-Cecchi \& Cinelli 1992, McCook \& Chapman 1993) remains unexplored in this system.

Because we examined recruitment within a multi-species assemblage, it is difficult to distinguish the individual contributions of the different species. The reproduction of species of Ascophyllum and Fucus shows a seasonal periodicity (M. Lamote pers. obs.), and the asynchronous phenology of the 3 species did allow some temporal separation of their relative contributions. Temperature responses of germlings appear to reflect the temperature range in the species season of reproduction (Steen \& Rueness 2004). Ascophyllum nodosum released gametes towards the end of June, followed by an abrupt loss of receptacles. This early reproduction combined with low abundance relative to the other species in these areas suggests that $A$. nodosum made a relatively small contribution to the recruits that we observed. Maturation and gamete liberation of Fucus vesiculosus started towards the end of July and continued into early autumn. This phenology combined with its higher abundance supports the idea that $F$. vesiculosus was the primary contributor to the high recruitment observed in August. Finally, F. distichus ssp. edentatus became reproductive in August and was probably responsible for most of the recruitment observed in September as seen in Area 5 where $F$. distichus was dominant and a clear peak in recruitment was seen in August 2000 (Fig. 1), the time at which this species was in peak reproduction.

The results of the present study demonstrate the large variability in the processes of recruitment, the fundamental step in maintaining populations of fucoids. Spatial and temporal variation appear to be a consistent feature of marine populations, but this variation is often attributed to the decoupling of local population processes due to the open nature of many marine species. Due to the limited dispersal of propagules in this system, there should have been less decoupling of the reproductive effort of the adults, the settlement of zygotes and the recruitment of juveniles, yet high temporal and spatial variation were still persistent features of the system.

Acknowledgements. The authors acknowledge the financial support of a grant from the Natural Sciences and Engineering Research Council (NSERC) of Canada (to L.E.J.) and fellowships and stipends from the Université Laval, Québec-Océan (formerly GIROQ), and Coopération Québec-France (to M.L.). W. Vincent, L. Lapointe, J. C. Dauvin, Y. Lemoine, G. Levavasseur, M. Durako, S. Brawley, and 2 anonymous reviewers provided constructive criticism on earlier drafts. G. Daigle gave valuable statistical advice.

\section{LITERATURE CITED}

Addy T, Johnson LE (2001) Littorine foraging behavior and population structure on a wave-exposed shore: non-linear responses across a physical gradient. J Shellfish Res 20: 385-391

Andersson S, Kautsky L, Kalvas A (1994) Circadian and lunar gamete release in Fucus vesiculosus in the atidal Baltic Sea. Mar Ecol Prog Ser 110:195-201

Ang PO (1991) Natural dynamics of a Fucus distichus population: reproduction and recruitment. Mar Ecol Prog Ser 78:71-85

Ang PO, De Wreede RE (1992) Density-dependence in a population of Fucus distichus. Mar Ecol Prog Ser 90:169-181

Archambault D, Bourget E (1983) Importance du regime de denudation sur la structure et la succession des communautés intertidales de substrat rocheux en milieu subarctique. Can J Fish Aquat Sci 40:1278-1292

Archambault P, Bourget E (1999) Influence of shoreline configuration on spatial variation of meroplanktonic larvae, recruitment and diversity of benthic subtidal communities. J Exp Mar Biol Ecol 238:161-184

Arrontes J (2002) Mechanisms of range expansion in the intertidal brown alga Fucus serratus in northern Spain. Mar Biol 141:1059-1067 
Barker KM, Chapman ARO (1990) Feeding preferences of periwinkles among four species of Fucus. Mar Biol 106: $113-118$

Benedetti-Cecchi L, Cinelli F (1992) Effects of canopy cover, herbivores and substratum type on patterns of Cystoseira spp. settlement and recruitment in littoral rockpools. Mar Ecol Prog Ser 90:183-191

Bourget E, Archambault D, Bergeron P (1985) Effet des propriétés hivernales sur les peuplements épibenthiques intertidaux dans un milieu subarticque, l'estuaire du Saint-Laurent. Nat Can 112:131-142

Brawley SH (1992) Fertilization in natural populations of the dioecious brown alga Fucus ceranoides and the importance of the polyspermy block. Mar Biol 113:145-157

Brawley SH, Johnson LE (1991) Survival of fucoid embryos in the intertidal zone depends upon developmental stage and microhabitats. J Phycol 27:179-186

Brawley SH, Johnson LE (1993) Predicting desiccation stress in microscopic organisms: the use of agarose beads to determine evaporation within and between intertidal microhabitats. J Phycol 29:528-535

Brawley SH, Johnson LE, Pearson GA, Speransky V, Li R, Serrão E (1999) Gamete release at low tide in fucoid algae: maladaptive or advantageous? Am Zool 39:218-229

Caffey HM (1984) Spatial and temporal variation in settlement and recruitment of intertidal barnacles. Ecol Monogr 55:313-322

> Cervin G, Lindegarth M, Viejo RM, Åberg P (2004) Effects of small-scale disturbances of canopy and grazing on intertidal assemblages on the Swedish west coast. J Exp Mar Biol Ecol 302:35-49

> Cervin G, Åberg P, Jenkins SJ (2005) Small-scale disturbance in a stable canopy dominated community: implications for macroalgal recruitment and growth. Mar Ecol Prog Ser 305:31-40

Chapman ARO (1995) Functional ecology of fucoid algae: twenty-three years of progress. Phycologia 34:1-32

Choat JH, Ayling AM, Schiel DR (1988) Temporal and spatial variation in an island fish fauna. J Exp Mar Biol Ecol 121: 91-111

> Creed JC, Norton TA, Kain JM (1996) Are neighbours harmful or helpful in Fucus vesiculosus populations? Mar Ecol Prog Ser 133:191-201

De Vogelaere AP, Foster MS (1994) Damage and recovery in intertidal Fucus gardneri assemblages following the Exxon Valdez oil spill. Mar Ecol Prog Ser 106:263-271

Dudgeon S, Petraitis PS (2001) Scale-dependent recruitment and divergence of intertidal communities. Ecology 82: 991-1006

Dudgeon SR, Kübler JE, Wright WA, Vadas RL Sr, Petraitis PS (2001) Natural variability in zygote dispersal of Ascophyllum nodosum at small spatial scales. Funct Ecol 15: 595-604

Edelstein T, McLachlan J (1975) Autoecology of Fucus distichus ssp. distichus (Phaeophyceae, Fucales) in Nova Scotia, Canada. Mar Biol 30:305-324

Hawkins SJ (1981) The influence of season and barnacles on the algal colonization of Patella vulgata exclusion areas. J Mar Biol Assoc UK 61:1-15

Johnson LE (1994) Enhanced settlement on microtopographical high points by the intertidal red alga Halosaccion glandiforme. Limnol Oceanogr 39:1893-1902

> Johnson LE, Brawley SH (1998) Dispersal and recruitment of a canopy-forming intertidal alga: the relative roles of propagule availability and post-settlement processes. Oecologia 117:517-526

> Kendrick GA (1994) Effects of propagule settlement density and adult canopy on survival of recruits of Sargassum spp.
(Sargassaceae: Phaeophyta). Mar Ecol Prog Ser 103: 129-140

Keough MJ, Downes BJ (1982) Recruitment of marine invertebrates: the role of active larval choices and early mortality. Oecologia 54:348-352

Kropf DL, Hopkins R, Quatrano RS (1989) Actin localization during Fucus embryogenesis. Plant Cell 1:191-200

Ladah L, Bermudez R, Pearson G, Serrão E (2003) Fertilization success and recruitment of dioecious and hermaphroditic fucoid seaweeds with contrasting distributions near their southern limit. Mar Ecol Prog Ser 262:173-183

Lamote M (2003) Suivi du recrutement des embryons de fucales dans leur milieu naturel et influence des stress de dessiccation et d'excès de lumière sur leur développement. PhD thesis, Université Laval, Quebec City, and Université de Lille I

Lamote M, Johnson LE, Lemoine Y (2007) Interspecific differences in the response of juvenile stages to physical sources of stress: fluorometric responses of fucoid embryos to variation in meteorological conditions. J Phycol 43: 1164-1176

Lazo L, Markham JH, Chapman ARO (1994) Herbivory and harvesting: effects on sexual recruitment and vegetative modules of Ascophyllum nodosum. Ophelia 40:95-113

Lubchenco J (1983) Littorina and Fucus: effects of herbivores, substratum heterogeneity, and plant escapes during succession. Ecology 64:1116-1123

McCook LJ, Chapman ARO (1991) Community succession following massive ice-scour on an exposed rocky shore: effects of Fucus canopy algae and of mussels during late succession. J Exp Mar Biol Ecol 154:137-169

> McCook LJ, Chapman ARO (1993) Community succession following ice-scour on a rocky intertidal shore: recruitment, competition and predation during early, primary succession. Mar Biol 115:565-575

- Norton TA (1992) Dispersal by algae. Br Phycol J 27:293-301

> Pearson GA, Brawley SH (1996) Reproductive ecology of Fucus distichus (Phaeophyceae): an intertidal alga with successful external fertilization. Mar Ecol Prog Ser 143: 211-223

> Pearson GA, Serrão EA (2006) Revisiting synchronous gamete release by fucoid algae in the intertidal zone: fertilization success and beyond? Integr Comp Biol 46:587-597

Quatrano RS (1980) Gamete release, fertilization and embryogenesis in the Fucales. In: Gantt E (ed) Handbook of phycological methods, developmental and cytological methods. Cambridge University Press, Cambridge, p 59-68

> Reed DC, Foster MS (1984) The effects of canopy shading on algal recruitment and growth in a giant kelp (Macrocystis pyrifera) forest. Ecology 65:937-948

Reed DC, Laur DR, Ebeling AW (1988) Variation in algal dispersal and recruitment: the importance of episodic events. Ecol Monogr 58:321-335

Roughgarden J, Gaines S, Possingham H (1988) Recruitment dynamics in complex life cycles. Science 241:1460-1466

Santelices B (1990) Patterns of reproduction, dispersal and recruitment in seaweeds. Oceanogr Mar Biol Annu Rev $28: 177-276$

Schonbeck MW, Norton TA (1980) The effects on intertidal fucoid algae of exposure to air under various conditions. Bot Mar 23:141-147

> Serrão EA, Pearson G, Kautsky L, Brawley SH (1996) Successful external fertlization in turbulent environments. Proc Natl Acad Sci USA 93:5286-5290

> Steen H, Rueness J (2004) Comparison and survival and growth in germling of six fucoid species (Fucales, Phaeophyceae) at two different temperatures and nutrient levels. Sarsia 89:175-183 
Steen H, Scrosati R (2004) Intraspecific competition in Fucus serratus and F. evanescens (Phaeophyceas: Fucales) germlings: effects of settlement density, nutrient concentration, and temperature. Mar Biol 144:61-70

Vadas RL, Miller S, Wright WA (1990) Recruitment in Ascophyllum nodosum Le jolis: wave action as a source of mortality. Mar Ecol Prog Ser 61:263-272

Vadas RL, Johnson S, Norton TA (1992) Recruitment and mortality of early post-settlement stages of benthic algae. $\mathrm{Br}$ Phycol J 27:331-351

Wilson J, Osenberg CI (2002) Experimental and observational patterns of density-dependent settlement and survival in the marine fish Gobiosoma. Oecologia 130: $205-215$

Editorial responsibility: Otto Kinne, Oldendorf/Luhe, Germany
Worm B, Chapman ARO (1996) Interference competition among two intertidal seaweeds: Chondrus crispus strongly affects survival of Fucus evanescens recruits. Mar Ecol Prog Ser 145:297-301

Worm B, Lotze HK, Sommer U (2001) Algal propagule banks modify competition, consumer and resource control on Baltic rocky shores. Oecologia 128:281-293

Wright JT, Steinberg PD (2001) Effect of variable recruitment and post-recruitment herbivory on local abundance of a marine alga. Ecology 82:2200-2215

- Wright JT, Williams SL, Dethier MN (2004) No zone is always greener: variation in the performance of Fucus gardneri embryos, juveniles and adults across tidal zone and season. Mar Biol 145:1061-1073

Submitted: April 26, 2005; Accepted: May 28, 2008 Proofs received from author(s): September 10, 2008 